\title{
Performance of soccer on the stock market: Evidence from Turkey
}

\author{
Hakan Berument $^{\mathrm{a}, *}$, Nildag Basak Ceylan ${ }^{\mathrm{b}}$, Esin Gozpinar ${ }^{\mathrm{a}}$ \\ ${ }^{a}$ Department of Economics, Bilkent University, 06800 Ankara, Turkey \\ ${ }^{\mathrm{b}}$ Department of Management, Atilim University, 06836 Ankara, Turkey
}

\begin{abstract}
This paper assesses the effect of soccer success on stock market returns for three major Turkish teams (Beşiktaş, Fenerbahçe and Galatasaray) after certain characteristics of the stock market are controlled for. The empirical evidence presented here suggests that Beşiktaş's win against foreign rivals in the Winner's Cup increases stock market returns. The same effect is not present for the other two big teams (Fenerbahçe and Galatasaray). The day of the week effect on the stock market and the relationship between risk and return are also presented.
\end{abstract}

(C) 2006 Elsevier Inc. All rights reserved.

\section{Introduction}

Behavioral finance has often promoted emotional and visceral factors as important determinants of asset pricing (see, for example, Stracca, 2004). Decision making agents appear to weight their objective probabilities subjectively under uncertainty. The probability weighting function may in turn depend on the agent's emotional state (see Loewenstein, 2000; Loewenstein, Weber, Hsee, \& Welch, 2001; Romer, 2000). Therefore, the status of the emotional stage affects asset prices.

Successes of major sports teams are important for a society and its morale. When their team wins, their supporters feel proud and happy. On the other hand, when a match is lost, they feel depressed and unhappy. Therefore, supporters might take different investment decisions depending upon the success of their teams. Ashton, Gerrard, and Hudson (2003) and Whitfield (2003) have pointed out that a good result in soccer affects a trader's moods or psychological well-being. He argues that buoyed brokers are more likely to behave bullish. On the other

\footnotetext{
* Corresponding author. Tel.: +90 312 2902342; fax: +90 3122665140.

E-mail address: berument@bilkent.edu.tr (H. Berument).
} 
hand, Edmans, García, and Norli (2005) note that daily stock returns decrease after a loss in the World Cup elimination matches.

In this study, the major Turkish soccer teams' (namely Beşiktaş, Fenerbahçe and Galatasaray) results in the Winner's Cup are used as a proxy for the trader's psychological well-being, and its effect on the stock market is analyzed by using a transfer function analysis. In particular, we assess what happens if a big team wins against a foreign rival. The empirical evidence presented here suggests that Beşiktaş's win against foreign rivals in the Winner's Cup increases stock market returns. The same effect is not present for the other two big teams (Fenerbahçe and Galatasaray).

\section{Method}

Transfer function analysis is often used in finance to account for irregularities (see, for example, Ahmad \& Ansari, 1997; Evans, 1990). In this paper, rather than using the autoregressive processes as a benchmark model, we used a Generalized Autoregressive Conditional Heteroscedasticity in Mean (GARCH-M) specification. The advantages of the GARCH-M compared to the autoregressive model are threefold. (1) It gives more efficient estimates. (2) It allows us to assess the effect of risk on return. (3) It provides a richer set of robustness statistics to model the return as a GARCH-M process.

We estimated the following specification

$$
\begin{aligned}
& R_{t}=\beta_{0}+\gamma X_{t}+\sum_{i=1}^{5} \beta_{i} R_{t-i}+\lambda h_{t}^{2}+e_{t}, \quad e_{t} \sim\left(0, h_{t}^{2}\right) \\
& h_{t}^{2}=\alpha_{0}+\alpha_{1 a} e_{t-1}^{2}+\alpha_{1 b} h_{t-1}^{2}
\end{aligned}
$$

where $R_{t}$ is defined as the logarithmic first difference of the ISE 100 index and $X_{t}$ includes sets of dummy variables for the day of the week effect and the success of the soccer teams. The first five lagged values for returns are also included in order to account for autocorrelation as suggested by the Final Prediction Error criteria, $h_{t}^{2}$ represents for the conditional variance that is captured by the $\operatorname{GARCH}(1,1)$ specification after a battery of estimations and $\lambda$ is the mean term to account for the effect of risk on return (one may view Enders, 1995, for details of the GARCH specifications).

\section{Empirical evidence}

The dataset for the stock market is gathered from the data delivery system of the Central Bank of the Republic of Turkey. The data on Fenerbahçe and Galatasaray are gathered from Tanrikulu (2002) and Tuncay (2001), respectively. This dataset for these two teams, as well as for Beşiktaş, are updated from http://www.hurriyetim.com. Lastly, we use dummy variables for the wins of the soccer teams. The dummy variable will take the value of one if a team wins, and zero otherwise. However, we assign the dummy variable as an observation for the next 
business day because the majority of the games were played outside the operating hours of the Istanbul Stock Exchange.

Table 1 reports the estimates of Eqs. (1) and (2) for the sample period between October 26th, 1987 and October 15th, 2003. The estimated coefficients for the day of the week variables are reported in the first five rows. The estimated coefficients for Monday and Tuesday are statistically significant at the $5 \%$ level, both having negative returns $(-0.47$ and -0.37 , respectively). The highest coefficients are observed for Friday and Thursday and the lowest coefficients are observed for Monday and Tuesday; the results are parallel to Balaban (1995).

The estimated coefficient for $\lambda$ (mean) is both positive and statistically significant at the $5 \%$ level. This supports the hypothesis that riskier assets must offer higher returns to be held. WIN is the variable regarding the number of wins of the three major soccer teams. This coefficient is negative and statistically insignificant at the $10 \%$ level. This does not support the hypothesis that wins in soccer increase returns in the stock market.

Supporters of each of the three major teams might have different economic and cultural backgrounds. Berument, Inamlik, and Yucel (2003) found that, of the top three soccer teams, the wins of Besiktas affected industrial production the most and the wins of Galatasaray had the least effect. Thus, we include the wins of these three teams separately. The estimates are reported in Column II. The empirical evidence suggests that Beşiktaş's wins affect returns most and the estimated coefficient is statistically significant at the 5\% level. The estimated coefficients for Fenerbahçe and Galatasaray are both negative but not statistically significant. Berument and Yucel (2005) argue that the location of wins is also important; wins in games played on the opponent's field increase industrial production more than if the win is realized at home. Thus, in Column III, we report the estimates with the location of wins (home and guest). Beşiktaş's guest wins increase the stock market returns more than home wins. The estimated coefficient for Beşiktaş's guest wins is statistically significant at the $10 \%$ level. The estimated coefficients for other teams have alternating signs, but they are not statistically significant at the $10 \%$ level.

\subsection{Robustness tests}

Muradoglu, Berument, and Metin (1999) specified the volatility equation for the Istanbul Stock Exchange as a $\operatorname{GARCH}(2,1)$ process for a shorter time span. In order to account for this, we estimated the whole model with the $\operatorname{GARCH}(2,1)$ specification. The analogue of the estimates are reported in Columns IV-VI. Overall, the basic evidence from Columns I-III are robust.

Next, we will elaborate on the variance specifications. Note that the estimated coefficients of the variance specifications are all positive. This satisfies the non-negativity constraint of the variances. Moreover, the sum of the estimated coefficients for the squared lag residuals and the lagged conditional variance(s) is less than one. This also satisfies the non-explosiveness of the variance specifications.

As a part of this study, we also tested how the losses and ties of the three major teams affect stock market returns. We could not find any statistically significant evidence for these at the $10 \%$ level (not reported). One reason for this is that, Turks do not expect their teams to beat their foreign rivals. Therefore, their team's not winning will not change their financial 
Table 1

Return statistics

\begin{tabular}{|c|c|c|c|c|c|c|}
\hline & I & II & III & IV & $\mathrm{V}$ & VI \\
\hline \multicolumn{7}{|l|}{ Mean specification } \\
\hline$M_{t}$ & $-0.47(-3.34)^{\mathrm{a}}$ & $-0.47(-3.29)^{\mathrm{a}}$ & $-0.45(-3.18)^{\mathrm{a}}$ & $-0.46(-3.25)^{\mathrm{a}}$ & $-0.45(-3.18)^{\mathrm{a}}$ & $-0.43(-3.08)^{\mathrm{a}}$ \\
\hline$T_{t}$ & $-0.37(-2.54)^{\mathrm{a}}$ & $-0.37(-2.52)^{\mathrm{a}}$ & $-0.35(-2.43)^{\mathrm{a}}$ & $-0.35(-2.43)^{\mathrm{a}}$ & $-0.35(-2.38)^{\mathrm{a}}$ & $-0.33(-2.30)^{\mathrm{a}}$ \\
\hline$W_{t}$ & $-0.23(-1.61)$ & $-0.23(-1.57)$ & $-0.21(-1.46)$ & $-0.22(-1.50)$ & $-0.21(-1.44)$ & $-0.19(-1.33)$ \\
\hline$H_{t}$ & $-0.15(-1.05)$ & $-0.14(-1.00)$ & $-0.13(-0.89)$ & $-0.14(-0.94)$ & $-0.13(-0.87)$ & $-0.11(-0.76)$ \\
\hline$F_{t}$ & $-0.09(-0.63)$ & $-0.09(-0.59)$ & $-0.07(-0.47)$ & $-0.08(-0.56)$ & $-0.07(-0.50)$ & $-0.06(-0.38)$ \\
\hline$R_{t-1}$ & $0.12(7.37)^{\mathrm{a}}$ & $0.12(7.40)^{\mathrm{a}}$ & $0.12(7.35)^{\mathrm{a}}$ & $0.12(7.31)^{\mathrm{a}}$ & $0.12(7.33)^{\mathrm{a}}$ & $0.12(7.28)^{\mathrm{a}}$ \\
\hline$R_{t-2}$ & $-0.01(-0.54)$ & $-0.01(-0.49)$ & $-0.01(-0.44)$ & $-0.01(-0.53)$ & $-0.01(-0.49)$ & $-0.01(-0.44)$ \\
\hline$R_{t-3}$ & $0.02(1.46)$ & $0.03(1.57)$ & $0.03(1.60)$ & $0.02(1.46)$ & $0.03(1.58)$ & $0.03(1.61)$ \\
\hline$R_{t-4}$ & $0.03(2.09)^{\mathrm{a}}$ & $0.03(2.03)^{\mathrm{a}}$ & $0.03(1.97)^{\mathrm{a}}$ & $0.03(2.07)^{\mathrm{a}}$ & $0.03(2.01)^{\mathrm{a}}$ & $0.03(1.95)^{\mathrm{a}}$ \\
\hline$R_{t-5}$ & $-0.01(-0.60)$ & $-0.01(-0.48)$ & $-0.01(-0.45)$ & $-0.01(-0.62)$ & $-0.01(-0.50)$ & $-0.01(-0.48)$ \\
\hline$h_{t}^{2}$ & $0.15(3.06)^{\mathrm{a}}$ & $0.15(3.01)^{\mathrm{a}}$ & $0.15(2.89)^{\mathrm{a}}$ & $0.15(2.94)^{\mathrm{a}}$ & $0.14(2.87)^{\mathrm{a}}$ & $0.14(2.76)^{\mathrm{a}}$ \\
\hline WIN & $-0.21(-0.68)$ & & & $-0.20(-0.65)$ & & \\
\hline Beşiktaş & & $1.35(2.08)^{\mathrm{a}}$ & & & $1.37(2.10)^{\mathrm{a}}$ & \\
\hline Fenerbahçe & & $-0.91(-1.07)$ & & & $-0.91(-1.05)$ & \\
\hline Galatasaray & & $-0.70(-1.46)$ & & & $-0.70(-1.45)$ & \\
\hline Home win (Besiktas) & & & $1.30(1.57)$ & & & $1.30(1.58)$ \\
\hline Guest win (Besiktas) & & & $2.42(1.70)^{\mathrm{a}}$ & & & $2.48(1.70)^{\mathrm{a}}$ \\
\hline Home win (Fenerbahce) & & & $2.55(0.68)$ & & & $2.55(0.67)$ \\
\hline Guest win (Fenerbahce) & & & $-2.07(-1.19)$ & & & $-2.07(-1.19)$ \\
\hline Home win (Galatasaray) & & & $-0.52(-0.90)$ & & & $-0.54(-0.93)$ \\
\hline Guest win (Galatasaray) & & & $-0.94(-1.06)$ & & & $-0.94(-1.04)$ \\
\hline \multicolumn{7}{|l|}{ Variance specification } \\
\hline Constant & $0.89(7.64)^{\mathrm{a}}$ & $0.89(7.62)^{\mathrm{a}}$ & $0.88(7.58)^{\mathrm{a}}$ & $0.91(6.83)^{\mathrm{a}}$ & $0.91(6.82)^{\mathrm{a}}$ & $0.90(6.79)^{\mathrm{a}}$ \\
\hline$e_{t-1}^{2}$ & $0.28(11.70)^{\mathrm{a}}$ & $0.28(11.63)^{\mathrm{a}}$ & $0.28(11.62)^{\mathrm{a}}$ & $0.29(9.28)^{\mathrm{a}}$ & $0.30(9.32)^{\mathrm{a}}$ & $0.30(9.34)^{\mathrm{a}}$ \\
\hline$h_{t-1}^{2}$ & $0.65(25.83)^{\mathrm{a}}$ & $0.65(25.76)^{\mathrm{a}}$ & $0.65(25.87)^{\mathrm{a}}$ & $0.54(4.83)^{\mathrm{a}}$ & $0.53(4.77)^{\mathrm{a}}$ & $0.53(4.75)^{\mathrm{a}}$ \\
\hline$h_{t-2}^{2-1}$ & & & & $0.09(1.06)$ & $0.10(1.17)$ & $0.11(1.22)$ \\
\hline$D^{-2}$ & $1.35(42.87)^{\mathrm{a}}$ & $1.34(43.00)^{\mathrm{a}}$ & $1.34(42.96)^{\mathrm{a}}$ & $1.35(42.67)^{\mathrm{a}}$ & $1.34(42.74)^{\mathrm{a}}$ & $1.34(42.68)^{\mathrm{a}}$ \\
\hline Log likelihood value & -10034.0 & -10030.6 & -10026.6 & -10030.5 & -10027.1 & -10023.0 \\
\hline
\end{tabular}

$t$-Ratios are reported in parentheses next the estimated coefficients.

${ }^{a}$ Indicates a $10 \%$ level of significance. 
behavior. However, wins affect the market participants. Secondly, parallel to house money (Thaler \& Johnson, 1990), agents might be more averse after a loss but risk taking after a gain. Therefore, wins increase risk taking behavior and encourage the participants to be bullish. After a loss, on the other hand, participants will be more risk averse.

\section{Conclusion}

This paper assesses the effect of soccer success on stock market returns after certain characteristics of the stock market are controlled for. The empirical evidence provided from Turkey in this paper suggests that Beşiktaş's win against foreign rivals in the Winners' Cup increased the stock market returns. The same effect is not present for the other two major Turkish teams (Fenerbahçe and Galatasaray). The day of the week effect on the stock market and the relationship between risk and return are also presented.

\section{References}

Ahmad, S. M., \& Ansari, M. I. (1997). Modelling the efficiency of the Canadian foreign exchange market: A bivariate transfer function analysis. Applied Economics, 29, 63-70.

Ashton, J. K., Gerrard, B., \& Hudson, R. (2003). Economic impact of national sporting success: Evidence from the London stock exchange. Applied Economics Letters, 10, 783-785.

Balaban, E. (1995). Day of the week effects: New evidence from an emerging market. Applied Economic Letters, $2,139-143$.

Berument, H., Inamlik, A., \& Yucel, E. M. (2003). The effect of soccer on productivity (in Turkish). Iktisat, İsletme ve Finans, 212, 51-62.

Berument, H., \& Yucel, E. M. (2005). Long live Fenerbahce: Production boosting effects of soccer in Turkey. Journal of Economic Psychology, 26, 842-861.

Edmans, A., García, D., \& Norli, Ø. (2005). Football and stock returns. Unpublished manuscript.

Enders, W. (1995). Applied Econometric Time Series. New York: John Wiley and Sons Press.

Evans, R. D. (1990). A transfer function analysis of real estate capitalization rates. Journal of Real Estate Research, 5, 371-379.

Loewenstein, G. F. (2000). Emotions in economic theory and economic behaviour. American Economic Review, $65,426-432$.

Loewenstein, G., Weber, E., Hsee, C., \& Welch, N. (2001). Risk as feelings. Psychological Bulletin, 127, 267-286.

Muradoglu, G., Berument, H., \& Metin, K. (1999). Financial crisis and changes in the determinants of risk and return: An empirical investigation of an emerging market. Multinational Finance Journal, 3, 223-252.

Romer, P. M. (2000). Thinking and feeling. American Economic Review Papers and Proceedings, 439-443.

Stracca, L. (2004). Behavioral finance and asset prices: Where do we stand? Journal of Economic Psychology, 25(3), 373-405.

Tanrikulu, A. (2002). History of Fenerbahçe with its legends, heroes and numbers (in Turkish). Istanbul: Yapi Kredi Cultural Press.

Thaler, R. H., \& Johnson, E. J. (1990). Gambling with the house money and trying to break even: The effects of prior outcomes on risky choice. Management Science, 36, 643-660.

Tuncay, B. (2001). History of Galatasaray: With European victories and unforgettable stars. Istanbul: Yapı Kredi Cultural Press.

Whitfield J. (2003) Football results kick share prices. Nature, published at News@ Nature. 